\title{
FOOD RESEARCH OPPORTUNITIES AND CHALLENGES: METHODS IN FOOD SAFETY AND FUNCTIONAL FOOD DEVELOPMENT: A REVIEW
}

\author{
Avo Karus, Virge Karus \\ Estonian University of Life Sciences, Estonia \\ avo.karus@emu.ee
}

\begin{abstract}
Large amounts of waste and by-products which are suitable for further use are generated in the food production chain. Globally, one-third of the food produced virtually becomes waste, in total 1.3 billion tonnes per year. The livestock sector is experiencing new challenges in the food and feed supply chain and waste valorization and there is a considerable diversity in animal origin food processing systems and broad knowledge base of expertise across Europe. However, due to local food production peculiarities, there is a considerable discrepancy in the waste management and processing methodology. An increasing amount of different novel feed and new functional food is available. These new products require a proper authentication and health and safety verification. Available know-how is increasing exponentially and therefore the potential for new and old bioactive component production from various currently poorly used materials is huge. Similarly, our knowledge about threats and food/feed safety is increasing. It is crucial to keep the balance between these processes. There are also several obstacles in data harmonization (data collection, used methodologies and reliability) and in data quality (lack of the comparability and completeness). The aim of the paper is to summarize the challenges in food research related to latest developments in methods.
\end{abstract}

Key words: animal by-products, food safety, food valorization, functional substances.

\section{Introduction}

Food security (or food insecurity) is a major challenge in the temporary world, as the global population is expected to exceed 9 billion by 2050 and thus, $60 \%$ increase in food production is needed compared to 2005 data (Augustin et al., 2016; $\mathrm{UN}, 2012)$. One option is to enhance the primary production, but there is another - the reduction of waste and/or the increased use of by-products and the reuse/valorization of waste (FAO, 2011; FAO et al., 2014). Large amounts of waste and by-products which are suitable for further use are generated in the food production chain. Globally, one-third of the food produced virtually becomes waste, in total 1.3 billion tonnes per year. The generation of animal waste in the EU is estimated at million tonnes per year or $180 \mathrm{~kg}$ per capita of which manufacturing sector produces $39 \%$. It consists of organic substances, which contain fat, protein, carbohydrates and often also important bioactive compounds. However, their use is still rather modest and there is no complex approach to this. The common technology for processing the by-products is not designed for an optimal use of protein-rich materials suitable for food and feed (connective tissue, tendons, bones, rind and blood) to reduce the deficit of food protein of animal origin. This is clearly unsustainable, since wasting food has serious social, environmental and economic impacts. The re-use and valorization of by-products and waste reduces environmental pollution and supplies energy production and industry with additional raw material and feed/food extra-production. Animal by-products (ABP) represent a wide group of different materials, which are ultimately linked to livestock production. ABP are defined as the entire bodies or parts of bodies of animals or products of animal origin not intended for human consumption, including ova, embryos and sperm. They represent more than 15 million tonnes of meat, dairy and other products, including manure. These materials are then disposed or processed and re-used in many different sectors, including the cosmetics or pharmaceuticals sectors, as well as being used for other technical purposes. The production flow of animal co-products and animal by-products is complex, including risk differentiation (categories). This means that about 75 million tons of ABP are produced per year worldwide, including Ca 15 million tons of processed animal protein (PAP) and 10 million tons of fat and tallow. These materials are then used in bioenergy production and feed, mainly pet food production. In Europe, the annual pet food production of over 8 million tons with the annual growth rate $2.0 \%$ (average value over 3 years). Another example is presented by the authorization of non-ruminant processed animal protein in fish feed in the EU. PAP is also able to contribute to the nutritional needs for calcium, phosphorous and vitamin B12 and therefore is a high-value resource of nutrients which is as safe as any other protein and cannot be regarded as a waste product by any means.

\section{Developments, Challenges and Opportunities}

An increase in production efficiency also means a decrease in waste generation. As the amount of waste is decreasing, it may also have a positive impact on environmental pressure, especially because arable land availability is decreasing (Shafiee-Jood \& Cai, 2016). There are three mainstreams to reach higher efficiency:

- to reuse by-products and waste for novel food production, 
- to produce feed (including pet food),

- to use them for technical (energy or fertilizers) purposes.

These three mainstreams are listed in order of relevance by actual political consensus in Europe. Technological processes are of primary importance to increase efficacy and there are new potential drivers in the process monitoring that will help us deal with challenges, mainly related to process monitoring and product safety. However, all these mainstreams do have potential difficulties in implementation and also potential threats. Numerous methods have been established to extract valuable bioactive compounds from food wastes; however, no single method can be regarded as a standard approach for extracting bioactive compounds because extraction methods are greatly affected by the food matrix and the bioactive compound to be extracted. To date, most of the extraction methods are based on solvent extraction, which impacts cost, safety, health and the environment. Adjusting the $\mathrm{pH}$ to high/low $\mathrm{pH}$ values for hydrolysis reactions are some common alternatives. The employment of enzymes in bioactive extractions is an alternative approach that can hold a lot of promise and could also minimise the drawbacks of $\mathrm{pH}$ assisted hydrolysis and solvent extraction methodologies. In addition to being effective at significantly small concentrations, enzymes are highly specific, versatile and relatively cheaper than organic solvents. On the other hand, the substitution of traditional solvent extraction processes for green processes based on the use of green solvents and intensified processes (such as microwave, ultrasound, and pressurized technologies) provides many advantages for the products obtained and the environment. Further, there is a strong need to establish sustainable approaches for the valorization of unutilized or low-value components from animal wastes into high-value bioproducts or components. For example, dairy by-products are the biggest group of undervalued materials of animal origin. Worldwide whey production is estimated at around 180 to $190 \times 10^{6}$ tons/year and only $50 \%$ of this is processed (in Europe more than 95\%). Approximately $50 \%$ of worldwide cheese-whey production is treated and transformed into various foods and feed products. However, cheese-whey is not the only dairy product that merits further investigations. Buttermilk as a by-product of butter making is presently under-utilised through processing into a relatively low-value commodity buttermilk powder. Nevertheless, recent findings have demonstrated that the milk fat globule membrane (MFGM) residue contained within buttermilk possesses biological activity and offers potential for greater commercial exploitation and added value in a safe way (Thompson, 2005).
Main challenges are related to product chemical and microbiological safety - especially if the valorization product presents ingredient for food or feed. Food/feed safety in global may create evidencebased concerns, but sometimes it may result from huge amount of data from different science fields, what may create doubts and questions. For example, in the study of IGF-1 as a mediator of growth hormone action in somatotropic axis in birds, polyunsaturated fatty acid (PUFA) feeding trials in quail was performed. First findings showed that both IGF-1 and muscle IGF-1 mRNA levels increased in early age. Statistical analyses and further experiments showed that $\omega$-3-PUFA additives in feed will downregulate IGF-1 gene-expression in leukocytes of female birds during finishing dietary period (days from 21 till 42) (Karus et al., 2007). Therefore, it might raise concerns about safety or at least about beneficial effect of food $\omega$-3-PUFA additives. However, no clear correlation between the growth of the birds and hepatic IGF1 mRNA expression and plasma IGF-1 levels was found. Insulin-like growth factor-1 did act there in paracrine manner. This study shows importance of an appropriate methodological study design, as in this study there was a clear advantage to measuring native free protein since the distribution of birds by mRNA level is significantly asymmetric, while native IGF1 protein content is still close to normal distribution (Karus et al., 2012). Inappropriate study design has had a major destructive effect in public awareness in the past (namely about GMO); therefore, all research results need to be carefully evaluated before making a decision.

Livestock sector is experiencing new challenges in the feed supply chain and waste valorization: increasing amount of different, novel feed and new functional food is now available. These products require a proper authentication and health and safety verification. Clearly, methods and protocols are required to characterise the ingredients of animal derivation as well to assess their effects on cell processes and gene expression in livestock animals. Furthermore, new byproducts may contain several types of contaminants and degradation products that may affect their potential re-use and valorization. In this connection the reduction and control of feed contaminants, such as toxins and residues, need to be addressed. This statement is also valid for other harmful biological agents (particularly pathogenic bacteria) and xenobiotics, including their possible carry-over from feed to food in the case of valorization of the ABP and waste processing and potential use. An important topic is also the development and validation of efficient analytical tools for the avoidance of health risks related to the presence of toxic contaminants or pathogenic agents' carry-over, cross-contamination etc. 
New opportunities in safety evaluation are provided by new analytical developments. NGS (Next Generation Sequencing) is decreasing the prices and time for sequencing and new algorithms allowed to analyse gut microbiota in hours, so we can expect to have it available also for food safety analyses in the near future. Nanosensors ('artificial nose') are capable of detecting metabolites of bacteria from air near skin or breath (Leja et al., 2016) - thus it opens the possibility to use similar technologies in food production facilities to prevent and detect food and feed contamination.

Due to unprecedented sensitivity, these methods have potential to create also enormous noisy data that may affect also the food safety. Spisak et al. (2013) published NGS study results reporting about big DNA fragments ability to pass from food to blood. This created a great public interest, but later it did not find confirmation, but a potential problem was supposed to be a widespread contamination (Lusk, 2014). Another comparative study in cross-contamination showed the scope of the problem. Approximately 80 percent of RNA samples collected from 180 different species as part of an evolutionary study became tainted with RNA sequences from other species, and most of this contamination occurred when the samples were sent to companies for sequencing (Ballenghien et al., 2017). They found that of 446 RNA samples sent for sequencing (representing 116 distinct species), 353 exhibited cross-species contamination and 205 of these samples were contaminated by at least two different species. However, similarly to arraybased tests, the qPCR is still not only valuable and affordable tool for validation of NGS and SMS (single molecule sequencing) data but can offer fast and simple tools for food safety control, especially if multiplexing is used (Cremonesi et al., 2014; Karus et al., 2017; Villamizar-Rodríguez et al., 2015). Thus, the modern methods can promote and assure better microbiological food safety, but they can also create an unnecessary public fear.

Next challenge is the quality of collected data data collection lacks an internationally harmonized approach as a limit to cooperation as well as it is an obstacle to improvements in risk assessment analysis (Nuttall et al., 2014). The only way to overcome this is to harmonize research and control methodology. Another side of this problem is the comparability of data and especially scientific data. It has also been called a publication bias: only statistically significant differences, changes, regressions, etc. are published, but non-significant results will not be published. Unfortunately, even when the scientists are willing to publish these data, it turns out to be impossible because of its low attractiveness and low potential for citation.

\section{Conclusions}

Valorization of food by-products and functional food development is a must by all means: food security, environmental sustainability, limits of energy resources etc. Know-how is increasing exponentially and therefore the potential for new and old bioactive component production from various currently poorly used materials is huge. Similarly, our knowledge about threats and food/feed safety is increasing. Therefore, the balance between these processes is crucial. Speed should be considered versus risk. Despite available latest technologies the methodology, transparency of data and critical use of obtained data remains crucial in evidence based decision-making process.

\section{References}

1. Augustin, M.A., Riley, M., Stockmann, R., Bennett, L., Kahl, A., Lockett, T., Osmond, M., Sanguansri, P., Stonehouse, W., Zajac, I., \& Cobiac, L. (2016). Role of food processing in food and nutrition security. Trends in Food Science \& Technology, 56: 115-125. DOI: 10.1016/j.tifs.2016.08.005.

2. Ballenghien, M., Faivre, N., \& Galtier, N. (2017). Patterns of cross-contamination in a multispecies population genomic project: detection, quantification, impact, and solutions. BMC Biology 15(1): 25.

3. Cremonesi, P., Pisani, L.F., Lecchi, C., Ceciliani, F., Martino, P., Bonastre, A.S., Karus, A., Balzaretti, C., \& Castiglioni, B. (2014). Development of 23 individual TaqMan ${ }^{\circledR}$ real-time PCR assays for identifying common foodborne pathogens using a single set of amplification conditions. Food Microbiol, 43, 35-40. DOI: 10.1016/j.fm.2014.04.007 PMid:24929880.

4. FAO (2011). Global food losses and food waste - extent, causes and prevention. Rome: FAO.

5. FAO, IFAD \& WFP. (2014). The State of Food Insecurity in the World 2014. Strengthening the enabling environment for food security and nutrition. Rome: FAO.

6. Hertel, T.W. (2015). The challenges of sustainably feeding a growing planet. Food Sec. 7:185-198. DOI: 10.1007/s12571-015-0440-2.

7. Karus, A., Saprõkina, Z., Tikk, H., Järv, P., Soidla, R., Lember, A., Kuusik, S., Karus, V., Kaldmäe, H., Roasto, M., \& Rei, M. (2007). Effect of Dietary Linseed on Insulin-Like Growth Factor-1 and Tissue Fat Composition in Quails. Archiv für Geflügelkunde / European Poultry Science, 71 (2), 81-87. 
8. Karus, A., Tikk, H., Lember, A., Karus, V., \& Roasto, M. (2012). IGF-1 free circulating protein and its geneexpression in linseed-rich diet quail. In: Pedro Rodrigues, David Eckersall and André de Almeida (Ed.). Farm animal proteomics (141-144). Wageningen: Wageningen Academic Publishers.

9. Karus, A., Ceciliani, F., Sanches Bonastre, A., \& Karus, V. (2017). Development of simple multiplex realtime PCR assays for foodborne pathogens detection and identification on LightCycler. Mac Vet Rev; 40 (1): DOI: 10.1515/macvetrev-2017-0010.

10. Leja, M., Amal, H., Lasina, I., Skapars, R., Sivins, A., Ancans, G., Tolmanis, I., Vanags, A., Kupcinskas, J., Ramonaite, R., Khatib, S., Bdarneh, S., Natour, R., Ashkar, A., \& Haick, H. (2016). Analysis of the effects of microbiome-related confounding factors on the reproducibility of the volatolomic test J. Breath Res. 10 (2016) 037101.

11. Lusk, R.W. (2014). Diverse and Widespread Contamination Evident in the Unmapped Depths of High Throughput Sequencing Data. PLoS ONE 9(10): e110808. DOI: 10.1371/journal.pone.0110808.

12. Nuttall, I., Miyagishima, K., Roth, C., \& de La Rocque, S. (2014). The United Nations and One Health: the International Health Regulations (2005) and global health security. Rev. sci. tech. Off. Int. Epiz. 33: 659-668.

13. Shafiee-Jood, M., \& Cai, X. (2016). Reducing Food Loss and Waste to Enhance Food Security and Environmental Sustainability. Environ. Sci. Technol. 50: 8432-8443. DOI: 10.1021/acs.est.6b01993.

14. Spisák, S., Solymosi, N., Ittzés, P., Bodor, A., Kondor, D., Vattay, G., Barták, B.K., Ferenc Sipos, F., Galamb, O., Tulassay, Z., Szállási, Z., Rasmussen, S., Sicheritz-Ponten, T., Brunak, S., Molnár, B., \& Csabai, I. (2013) Complete Genes May Pass from Food to Human Blood. PLoS ONE 8(7): e69805. DOI: 10.1371/journal.pone.0069805.

15. Thompson, A.K. (2005). Structure and properties of liposomes prepared from milk phospholipids. PhD thesis. Massey University, Massey, New Zealand. Retrieved February 2, 2018, from: https://mro.massey. ac.nz/bitstream/handle/10179/3459/02_whole.pdf?sequence=1\&isAllowed=y.

16. UN World Food Program (2012). Retrieved 12 January, 2018, from: https://www.unbrussels.org/worldfood-programme-wfp/.

17. Villamizar-Rodríguez, G., Fernández, J., Marín, L., Muñiz, J., González, I., \& Lombó, F. (2015). Multiplex detection of nine food-borne pathogens by mPCR and capillary electrophoresis after using a universal preenrichment medium. Front. Microbiol. 6:1194. DOI: 10.3389/fmicb.2015.01194. 